\title{
Communicable Diseases
}

\section{Epidemic of gastroenteritis caused by oysters contaminated with small round structured viruses}

\author{
O N GILL, W D CUBITT, D A McSWIGGAN, B M WATNEY, C L R BARTLETT
}

\begin{abstract}
A large outbreak of viral gastroenteritis occurred in which oysters eaten raw were the vehicle of infection. Laboratory findings indicated that a small round structured virus was the infecting agent. Adults of all ages were equally susceptible to infection with the virus. Investigation cast doubt on the efficacy of depuration as a method for rendering oysters free of virus, and hence the public should be warned of the hazard of eating raw shellfish.
\end{abstract}

\section{Introduction}

Eight receptions held in the afternoons and evenings during one week in January 1983 at a single premises in Tower Hamlets, London, were attended by about 1300 people. By the beginning of the following week several of the guests, all of whom had eaten oysters, had suffered a bout of diarrhoea and vomiting. An epidemiological investigation was therefore undertaken to determine the association of this illness with the consumption of oysters.

\section{Methods of investigation}

During the week after the receptions a cohort study was conducted using a questionnaire asking about the occurrence of illness, symptoms, time of onset, absence from work owing to sickness, illness among home contacts, and consumption of food and drink. Because of the large number of people exposed the questionnaire was sent only to the 495 people who had attended the first and last receptions, although illness had occurred after the other receptions. Certificates of sickness absence were examined for cases of jaundice occurring during a seven week follow up period.

Faecal samples were obtained between three and 15 days after the onset of illness (median 9 days) from 14 ill people (five from the first

PHLS Communicable Disease Surveillance Centre, London NW9 5EQ

O N GILL, MB, MSC, senior registrar in community medicine (epidemiology) C L R BARTLETT, MSC, FFCM, specialist in community medicine (epidemiology)

Public Health Laboratory, Central Middlesex Hospital, Park Royal, London NW10 7NS

W D CUBITT, MSC, MIBIOL, senior microbiologist

D A MCSWIGGAN, FRCPATH, director

Hampstead, London NW3

B M WATNEY, MB, MFOM, consultant in occupational medicine

Correspondence to: Dr O N Gill. reception, seven from the last reception, and two from people who, although not at the receptions, developed symptoms after illness in their spouses who had been guests). Faecal samples were also obtained from 12 well people, six from each reception, between five and 12 days after the receptions (median 7 days).

Paired sera were collected from 17 ill people and 20 well people, and convalescent sera only from two other ill people. Acute phase or initial samples were collected between three and 10 days (median 8 days) after the onset of illness and the convalescent phase samples two to four weeks later. The early sera from the well people were collected between five and 12 days after the receptions (median 7 days), and the late samples after a two week interval.

Faecal samples were emulsified in a drop of potassium phosphotungstic acid, $\mathrm{pH} 6.4$, placed on a carbon-formvar coated grid and examined in a Philips EM 201 electron microscope for virus particles. Specimens in which viruses were not detected by the procedure were emulsified in phosphate buffered saline and then treated with chloroform. The supernatant was removed and treated several times with trichlorotrifluoroethane. The aqueous layer was filtered through a $0 \cdot 2 \mu \mathrm{m}$ membrane and spun in an SW 50:1 rotor at $84000 \mathrm{~g}$ for two hours. The pellet was resuspended and examined.

Faecal suspensions were inoculated on to primary baboon kidney and human embryo kidney cells and examined for cytopathic effects over 14 days; cultures were passaged on day 7 . All faecal samples were screened for shigellas, salmonellas, campylobacters, and Aeromonas hydrophila using standard laboratory techniques.

A pool of antigen was prepared from the stools of three patients who were found to be excreting large numbers of virus particles. Sera were tested in a series of doubling dilutions from $1 / 20$ to $1 / 640$ by immune electron microscopy. ${ }^{1}$ Sera from patients who presented with symptoms suggestive of hepatitis were tested for hepatitis A IgM by radioimmunoassay.

The bacterial monitoring records of oysters from the oyster farm, before and after depuration, were reviewed.

\section{Results}

EPIDEMIOLOGICAL

Replies were received from 319 of the 343 subjects ( $93 \%$ ) who had attended the first reception and from 132 of the 152 subjects $(87 \%)$ from the last reception; of the 451 responders, $181(40 \%)$ were ill, 133 $(42 \%)$ after the first reception and $48(36 \%)$ after the last reception. The principal clinical features were anorexia, nausea, diarrhoea, and fever (table I), although aching limbs, abdominal pain, and vomiting were also common. The mean incubation periods in the two cohorts were 38 hours and 40 hours respectively; 115 subjects $(64 \%)$ had their onset of illness between 24 and 48 hours, 14 within 12 hours, and nine over 72 hours after the meal. Only one case of jaundice occurred among the 495 subjects during the seven weeks of follow up; this person ate oysters, had gastroenteritis shortly afterwards, and developed hepatitis $\mathrm{A}$ (IgM positive) 40 days after the reception. The gastroenteritis caused appreciable absence from work; two thirds of those ill were absent for one day or more, and one third were absent for two days or more. On average 1.15 working days were lost by each ill person. One person was admitted to hospital.

In the calculation of food specific attack rates a restricted case definition was used to exclude the more subjective symptoms; this 
defined cases as people with diarrhoea or vomiting or abdominal pain beginning within 72 hours. Of 181 people who complained of any form of illness, $152(84 \%)$ of them satisfied this definition (table I). Although 17 different items of food were served, and seven of these were more popular than the oysters, the results strongly suggested that Pacific oysters (Crassostrea gigas) were the vehicle of infection (table II); the relative risk of illness associated with consumption of oysters was 16, and no other food was associated with illness. Eating a single oyster was enough to cause illness in 11 of the 16 people who did so. Those who ate many oysters did not have a shorter incubation period than those who ate only a few. Of people eating oysters, those not drinking alcohol were just as likely to become ill as those drinking moderate or heavy amounts. Neither of the two men who opened and served the oysters was ill at the time. The people known to have had gastroenteritis after the other receptions had eaten oysters; of a small party of six people who attended the second reception, the four who ate oysters became ill two days later; a further three people who ate oysters at the fourth reception became ill.

There was no evidence of age related immunity; the attack rate among those aged over 45 who ate oysters was as high as in those younger than 26 (table III). A similar illness, occurring one or two days later, was reported among 32 home contacts ( 26 adults, six children) of the 181 primary cases; incomplete information prevented the calculation of secondary attack rates.

TABLE I-Characteristics of illness in subjects who had attended one or other of the two receptions

\begin{tabular}{lcc}
\hline Symptoms & $\begin{array}{c}\text { No }(\%) \text { reporting } \\
\text { symptom; }\end{array}$ & $\begin{array}{c}\text { No with this } \\
\text { symptom only }\end{array}$ \\
\hline Loss of appetite & $135(75)$ & 1 \\
Nausea & $130(72)$ & 3 \\
Diarrhoea & $119(66)$ & 0 \\
Fever & $118(65)$ & 4 \\
Abdominal pain & $109(60)$ & 2 \\
Aching limbs & $101(56)$ & 0 \\
Vomiting & $94(52)$ & 1 \\
Other & $58(32)$ & 0 \\
Restricted case* definition & $152(84)$ & \\
$\quad$ Total ill & $181(100)$ & \\
\hline
\end{tabular}

* Diarrhoea or vomiting or abdominal pain, or all three, within 72 hours.

TABLE II-Rate of illness and exposure to oysters (both receptions)

\begin{tabular}{lcrc}
\hline & $\begin{array}{c}\text { No ill } \\
\text { (restricted* } \\
\text { definition) }\end{array}$ & No well & Total $\dagger$ \\
\hline Ate oysters & 137 & 36 & 173 \\
Did not eat oysters & 13 & 255 & 268 \\
\hline
\end{tabular}

* Diarrhoea or vomiting or abdominal pain, or all three, within 72 hours $\left(\chi^{2}=259 ; \mathrm{p}<0.0001\right)$

$\dagger$ In 10 subjects data were not obtained.

TABLE III-Absence of age related immunity*

\begin{tabular}{lcccccc}
\hline & \multicolumn{2}{c}{ Total who ate oysters } & & \multicolumn{2}{c}{ Those who did not eat oysters } \\
\cline { 2 - 3 } \cline { 6 - 7 } Age group (years) & Total No & No $(\%)$ ill & & Total No & No (\%) ill \\
\hline$\leqslant 25$ & 23 & $21(91)$ & & 33 & $6(18)$ \\
$26-35$ & 32 & $25(78)$ & & 58 & $5(9)$ \\
$36-45$ & 42 & $36(86)$ & & 70 & $10(14)$ \\
$>45$ & 75 & $64(85)$ & & 99 & $8(8)$ \\
\hline
\end{tabular}

* Data not obtained in 11 subjects.

\section{LABORATORY}

The definition of a small round structured virus infection was the finding of particles of such a virus in the faeces or a fourfold or greater rise in antibody levels between acute and convalescent sera or convalescent serum with an antibody titre of 320 or greater. There was a close relation between small round structured virus infection, persons with an illness satisfying the restricted case definition, and consumption of oysters (table IV); of the 21 subjects who ate oysters, 19 became ill and 16 of them had confirmed small round structured virus infection.
TABLE IV-Laboratory results, illness, and consumption of oysters

\begin{tabular}{|c|c|c|c|c|c|}
\hline \multirow{2}{*}{ Oyster consumption } & \multicolumn{2}{|c|}{$\begin{array}{c}\text { Laboratory proved* } \\
\text { infection with small } \\
\text { round structured viruses }\end{array}$} & \multicolumn{2}{|c|}{ No laboratory evidence } & \multirow[b]{2}{*}{ Total } \\
\hline & $\begin{array}{c}\text { No ill } \\
\text { (restricted } \\
\text { definition) }\end{array}$ & No well & $\begin{array}{c}\text { No ill } \\
\text { (restricted } \\
\text { definition) }\end{array}$ & No well & \\
\hline $\begin{array}{l}\text { Ate oysters } \\
\text { Did not eat oysters }\end{array}$ & $\begin{array}{r}16 \\
0\end{array}$ & $\begin{array}{l}0 \\
1\end{array}$ & $\begin{array}{l}3 \\
0\end{array}$ & $\begin{array}{r}2 \\
17\end{array}$ & $\begin{array}{l}21 \\
18\end{array}$ \\
\hline Total & 16 & 1 & 3 & 19 & 39 \\
\hline
\end{tabular}

* Small round structured viruses in acute stool specimens or fourfold rise in antibody titre or convalescent titre equal to or greater than 320, on all three. Using Fisher's round structured virus and illness was highly significant $(p<0.0001)$.

Small round structured virus particles, measuring 30-35 nm diameter (figure), were detected in faecal specimens from four of 14 ill people, one from each reception and from the two secondary cases who supplied specimens. Small round structured virus particles were not seen in the faecal specimens of the 12 well people. One other ill person was excreting echovirus type 5 and Salmonella mbandaka. No other pathogenic agents were detected in any of the faecal specimens examined.

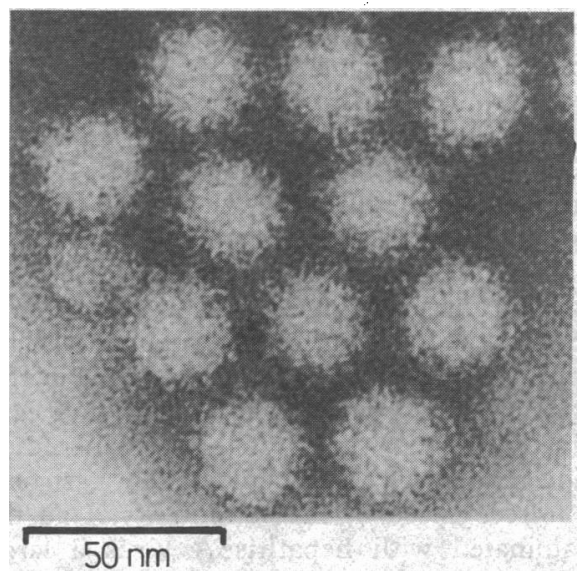

Small round structured viruses from one of the cases. $\times 380000$ (original magnification).

A fourfold or greater rise in antibodies against the small round structured virus was shown by immune electron microscopy in six out of nine people ill after the first reception and in seven out of 10 ill after the last reception but in only one of the 20 well people examined. Convalescent titres of 320 or greater were found in 10 of the 19 ill people but in none of the 20 well people. The geometric mean titre of antibody in the acute sera from 17 ill people was 40 , similar to that (35) of the early specimens from the 20 well people. In contrast, the geometric mean titre of convalescent sera from 19 ill people was 222, much higher than the geometric mean titre of 38 in the late specimens from the 20 well people (two sample $t$ test; $\mathrm{p}<0 \cdot 001$ ).

\section{ENVIRONMENTAL}

A total of 4900 Pacific oysters ( $C$ gigas) were imported for the four days of receptions; they were transported direct from the fishery and stored in plasticised cardboard containers at $5-10^{\circ} \mathrm{C}$ in refrigerated trucks for one to three days before consumption. Local water was not added to the containers at any time and most of the oysters were opened and served direct from the containers; a few were opened and immersed in loose ice before serving.

After harvesting, the oysters had been treated by depuration for 72 hours in a 5500 litre seawater tank; about 8000 oysters had been placed in the tank and the water circulated continuously through a 30 watt ultraviolet light sterilisation plant at 2730 litres an hour; the average depuration rate was $0.351 /$ oyster/hour. The tank water was circulated through the ultraviolet light for 48 hours before the introduction of the oysters. Depurated oysters had been independently monitored by a hospital laboratory on behalf of the local borough council since 1977; of the 78 samples tested at regular intervals, only three had more than 
five faecal coliforms per $\mathrm{ml}$ and two of these three samples had more than 15 faecal coliforms per $\mathrm{ml}$. Oysters sampled direct from the layings were tested on 43 occasions; five samples had more than five faecal coliforms per $\mathrm{ml}$ and one of these had more than 15 faecal coliforms per ml. All the oyster samples with more than five faecal coliforms per ml were collected six months or more before the outbreak; seven seawater samples, taken from the bay area, had fewer than 10 faecal coliforms per $100 \mathrm{ml}$. After the outbreak a seawater sample taken from the bay and a water sample from the river draining into the bay had between 1500 and 2000 faecal coliforms per $100 \mathrm{ml}$.

\section{Discussion}

In this outbreak the epidemiological investigation strongly suggested that contaminated oysters were the vehicle of infection. The laboratory results indicated that small round structured virus particles were the infecting agents and the outbreak had a "Norwalk like" pattern as judged by recognised criteria." The high attack rate in people who had eaten oysters $(79 \%)$ was similar to that found in earlier outbreaks of non-bacterial gastroenteritis associated with oysters. ${ }^{3-5}$ This finding and the absence of age related immunity suggest that most adults are susceptible to infection with the virus.

The 181 affected people had eaten about 950 oysters (average $5 \cdot 2$ each). Altogether 208 working days were lost and secondary spread within households increased the impact of the outbreak. As 12000 oysters were distributed from the fishery during that one week, possibly some 2300 people might have been affected causing a loss of 2650 working days. Oysters from the same fishery were associated with three other small outbreaks of nonbacterial gastroenteritis in November 1982 (PHLS Communicable Disease Report 82/45, unpublished) and February 1983 , and small round structured virus was found in one of these episodes. Because of the length of the incubation period and the relative prominence of flu like symptoms, many of those affected in our outbreak had not linked their illness with eating oysters, as contaminated oysters were probably distributed over a much longer period than one week, an epidemic of gastroenteritis may have gone unrecognised in the community. Had these oysters been contaminated with hepatitis A virus a large outbreak similar to that recently described involving cockles might have occurred. ${ }^{6}$

Though sources of sewage pollution existed within 4 kilometres of the oyster layings associated with this outbreak, there was no evidence of faecal contamination in the occasional bacterial monitoring of the sea water before the outbreak. Besides, longitudinal studies show that monitoring faecal coliforms is an inadequate predictor of viral contamination in sea water. ${ }^{7} 8$

The oysters in our outbreak were depurated for at least 72 hours in a system which was functioning correctly as judged by bacterial monitoring. Acute non-bacterial gastroenteritis associated with depurated oysters was described in England in 1967, ${ }^{3}$ although the aetiological agent was not identified. After a large outbreak in Australia ${ }^{9}$ the depuration process introduced failed to prevent further illness from oysters grown in waters which might have been contaminated with faeces."

Satisfactory procedures for eradicating viruses from shellfish are unavailable at present. Virus particles contaminating oysters have survived steaming for 30 minutes ${ }^{11}$ and commercial cooking as currently practised is often unsuccessful at rendering contaminated cockles free of hepatitis A virus. ${ }^{12}$ Freezing of oysters does not interrupt transmission; an outbreak of Norwalk agent gastroenteritis in Australia occurred after the consumption of oysters which had been frozen for over three months.

There is an urgent need to devise depuration procedures or other treatment methods which are effective at removing viral contamination from oysters. Meanwhile, oysters for human consumption, harvested from waters into which sewage is discharged, are a risk to public health. All oysters sold to the public should be traceable directly to the oyster laying where they were harvested, and to facilitate this a batch system with records linking fishery to retailer should be introduced. When epidemiological evidence establishes that depurated oysters from particular oyster layings are contaminated, harvesting of oysters from these layings should stop. The public should be aware that at present no guarantee can be given about the safety of eating raw shellfish.

We thank the following who contributed to the investigation: Miss C Jenkinson and Mrs M Phillips, occupational health nurses; Mr R Horton, deputy $\mathrm{CEHO}$, and $\mathrm{Dr} M$ Heath, MOEH for Tower Hamlets; the public health department that investigated the oyster fishery; $\operatorname{Dr} T S$ Wilson for allowing us to quote the results of the bacterial monitoring of the oyster fishery; Dr E M Vandervelde for serological investigation of the patient with hepatitis A; and Miss J White for her contribution to the data processing.

\section{References}

${ }^{1}$ Cubitt WD, McSwiggan DA, Moore W. Winter vomiting disease caused by calicivirus. $\mathcal{F}$ Clin Pathol $1979 ; 32: 786-93$

${ }^{2}$ Kaplan JE, Feldman R, Campbell DS, Lookabaugh C, Gary GW. The frequency of a Norwalk-like pattern of illness in outbreaks of acute gastroenteritis. Am f Public Health 1982;72:1329-32.

${ }^{3}$ Gunn ADG, Rowlands DF. A confined outbreak of food poisoning. Medical Officer 1969;122:75-9.

+ Appleton H, Palmer SR, Gilbert RJ. Foodborne gastroenteritis of unknown aetiology: a virus infection? $\mathrm{Br}$ Med F $1981 ; \mathbf{2 8 2}: 1801-2$.

${ }^{5}$ Linco SJ, Grohmann GS. The Darwin outbreak of oyster associated viral gastroenteritis. Med f Aust 1980;i:211-3.

${ }^{6}$ O'Mahony MC, Gooch CD, Smyth DA, Thrussell AJ, Bartlett CLR, Noah ND. Epidemic hepatitis A from cockles. Lancet 1983;i:518-20.

Gerba CP, Goyal SM, LaBelle RL, Cech I, Bodgan GF. Failure of indicator bacteria to reflect the occurrence of enteroviruses in marine waters. Am ₹ Public Health 1979;69:1116-9.

${ }^{8}$ Ellender RD, Mapp JB, Middlebrooks BL, Cook DW, Cake EW. Natural enteroviruses and faecal coliform contamination in Gulf Coast oysters. fournal of Food Protection 1980;43:105-10.

${ }^{9}$ Murphy AM, Grohmann GS, Christopher PJ, Lopez WA, Davey GR, Millsom RH. An Australia-wide outbreak of gastroenteritis from oysters caused by Norwalk virus. Med f Aust 1979;ii:329-33.

10 Grohmann GS, Murphy AM, Christopher PJ, Auty E, Greenberg HB. Norwalk virus gastroenteritis in volunteers consuming depurated oysters. Australian fournal of Experimental Biology and Medical Science $1981 ; 59: 2,219-28$.

" DiGiorolamo R, Liston J, Matches JR. Survival of viruses in chilled, frozen and processed oysters. Applied Microbiology $1970 ; 20: 1,58-63$.

1.2 Anonymous. The cooking of cockles. [Editorial.] Lancet 1983;i:513.

(Accepted 24 August 198.3)

\section{Indian reflections: crossing the border}

I had nothing to do but hold your hand and watch you ebbing away. I was aware that the flicker of life was going out and the ultimate time had come. Your destination was in sight and you were very weak. I held your hand because I felt, maybe erroneously, that you needed support in the last few remaining steps required to cross the border. There was no way of knowing if you felt my touch. I regarded your face, it was so serene that I could not fathom what you were experiencing. Probably you had already transcended and you were beyond human reach. If you wished to say anything I would never know. But I had so much to say and there was no time. It was like starting to narrate a story to someone you had come to see off and the train starts pulling out. But I still desperately wished to convey all that was within me and there was no time for words. Then it dawned that I had a part of you within me which could communicate with you. So I contemplated in silence, alone, in that room still holding your hand. It was the only way I could convey so much in so little a time. It was a communion. I hope I did not disturb you in the ecstatic state you probably had already reached.

Then the flicker went out, I had seen you cross the border. I had to stop for I could not go beyond.

Did my thoughts reach you?

I hope they did, Mother.

S K MAJUMDAR, director, HHRD Medical Trust, Jodhpur, Rajasthan, India. 